Original Research Paper

\title{
Construction of Decision-Making Model to Select Incentive Tour Travel Agencies
}

\author{
${ }^{1}$ Han-Chen Huang, ${ }^{2}$ Pei-Ying Wu, ${ }^{3}$ Su-Ling Wu, ${ }^{4}$ Chin-Yuan Wu \\ ${ }^{1,2}$ Department of Tourism and MICE, Chung Hua University, Taiwan \\ ${ }^{3,4}$ Department of Leisure Management, Yu Da University of Science and Technology, Taiwan
}

\author{
Article history \\ Received: 07-08-2015 \\ Revised: 06-10-2015 \\ Accepted: 17-10-2015 \\ Corresponding Author: \\ Chin-Yuan $\mathrm{Wu}$ \\ Department of Leisure \\ Management, Yu Da University \\ of Science and Technology, \\ Taiwan \\ Email: omgpaperei@gmail.com
}

\begin{abstract}
Incentive Tour is a business trip that aims to enhance corporate cohesion, reinforce corporate culture and develop or strengthen the market. The subjects include employees, suppliers, distributors, etc. The Incentive Tour of enterprises is different from general group tours and becomes one of the mainstream methods to stimulate employees. However, few studies probed into the manipulation of the Incentive Tour from the perspective of enterprises. Therefore, in terms of demand, this study explores the construction of a decision-making model to select Incentive Tour travel agencies. The subjects were the persons in charge of travel agencies with an Incentive Tour department, as well as the main business of Incentive Tour and enterprises that have experience with Incentive Tour. An expert questionnaire survey was conducted and data were analyzed by the Analytic Hierarchy Process (AHP). According to the findings, among the factors to select Incentive Tour travel agencies, specialty of the team and activity planning are the most important factors, followed by food planning, hotel planning and transportation planning. The findings can serve as reference for enterprises when selecting Incentive Tour travel agencies.
\end{abstract}

Keywords: Incentive Tour, Travel Agencies, Modified Delphi Method, Analytic Hierarchy Process

\section{Introduction}

With economic development, the Incentive Tour becomes more important in the travel market. According to SITE (2014), in the U.S., 89\% of employees suggest that performance depends on the employers' effective rewards, meaning appropriate rewards will improve employees' work quality and enhance productivity. Therefore, the Incentive Tour becomes one of the mainstream methods for enterprises to stimulate employees.

Chang and Chen (2008) indicated that the Incentive Tour is a new type of travel. It was launched in 1950s and became popular in 1960. Different from general group travel, it is usually based on rewards and specific purposes and is not simple tourism. Therefore, the selection of locations, arrangement of itineraries, food and hotels are different thus, the travel industry should have proper planning regarding the Incentive Tour of enterprises, such as itinerary design and new manipulation and marketing strategies, which should be different from general group tours.
In Taiwan, most travel agencies treat the Incentive Tours of enterprises as general group tours without additional services, such as group ticketing and group food reservations. By determining the needs of enterprise, they can provide high-quality travel activities and experiences, which leads to a win-win state.

Therefore, this study conducts pretest questionnaire by expert interview with the supervisors of enterprises with the experience of Incentive Tours, reorganizes expert opinions to determine the proper selection factors and explores the relative weights by Analytic Hierarchy Process (AHP), in order to generalize the factors required to construct a decision-making model to select Incentive Tour travel agencies. Finally, the researcher concludes the findings and prepares the paper.

The main research purposes are shown as follows:

- According to enterprise owners' needs, it focuses on the indicators to construct a selection of Incentive Tour travel agencies

- It probes into the weights of indicators in the decision-making model to select Incentive Tour 
travel agencies and establishes objective selection according to the result

- According to the findings and suggestions, it serves as reference for firms in Taiwan to select Incentive Tour travel agencies

\section{Literature Review}

The literature review explores the decision-making factors to construct a selection model for Incentive Tour travel agencies, including 3 parts:

- Study on factors of enterprises' selection of Incentive Tour travel agencies

- Modified Delphi Method

- AHP

\section{Study on the Construction of a Decision-Making} Model to Select Incentive Tour Travel Agencies

Chen (2002) suggested that the Incentive Tour is a kind of management tool and defined the Incentive Tour as a modern management tool, which purpose is to help enterprises accomplish specific business goals. Those who accomplish the goals will be rewarded by an extraordinary trip. In addition, she mentioned that besides general spots, the "party" is also key, as it can demonstrate the effort and creativity of the host. Hence, the design and arrangement of Incentive Tours are different from general group tours for employees, as it requires more experts and creativity.

Based on the research of Hastings et al. (1988), Incentive Tours aim to stimulate people and thus, they defined the Incentive Tour as a technique of stimulation, meaning it uses the tour as a trophy for the participants.

Chiang (2004; Yung et al., 2008) suggested that Incentive Tours serve as a reward and defined the Incentive Tour as a reward for those who accomplish business goals and contribute to the firms. The enterprises plan overseas trips as incentives.

According to the STB (2014), the Incentive Tour is not a general employee trip Hampton (1987). The research of Stolovitch (2002) indicated that the purpose of an Incentive Tour is diverse, as it enhances employees' performance and reinforces colleagues' cohesion. It can also provide an opportunity for group learning. The characteristics are shown, as follows: it is not a general employee trip, it creates corporate culture and is professional manipulation.

Wang (2009) defined Incentive Tour was the reward of enterprises for employees who accomplish business goals and the tour is precisely planned and the enterprises totally or partially pay for the trip, which can stimulate employees.

The TBMOTC (2009), suggested that a successful Incentive Tour relies on the support of firms, team work and flexibility. Thus, the travelers will experience high-quality service.

\section{Modified Delphi Method}

The Delphi Method was constructed by Helmer and Gordon in 1940s. In 1946, in order to avoid submission to authority or blindly following the majority in group discussions, the RAND Corporation of the U.S. first adopted and commonly used this method. In the middle of the 20th century, when the American government launched the North Korean War, the RAND Corporation proposed a prediction of the failure of the war. The government did not accept it and encountered defeat. Hence, the Delphi Method was widely recognized.

The Delphi Method was first applied in technology and was gradually adopted for predictions in various fields, such as military predication, population prediction, medical prediction, operation and demand prediction, education prediction, etc. In addition, it is used for evaluation, decision-making, management communication and planning.

According to Murry and Hammons (1995), the Delphi Method invites anonymous experts to participate in the prediction and fully uses the experts' experience and knowledge. Hence, each expert can freely and independently offer judgment. After several rounds of feedback, they find a common consensus, which becomes an effective prediction.

The process of the Delphi Method is repeated written communication and opinion expression to obtain experts' consistent views. However, due to time, labor and funds, the adjusted process for successful research is the "Modified Delphi Method". Due to special concerns, some studies modified the steps of the typical Delphi Method by skipping brainstorming and the open-ended questionnaire survey. After reviewing and revising great numbers of literature, they directly developed a structural questionnaire as the first-round questionnaire. Murry and Hammons (1995) suggested that the advantage of conducting a first-round survey through a structural questionnaire is saved time. By structural questionnaire, the participating experts focus on the research topic and will not question the open-ended questionnaire.

\section{Analytic Hierarchy Process (AHP)}

Professor Thomas L. Saaty of the University of Pittsburgh proposed AHP in 1971. After 1980, the theory of AHP was more complete (Saaty, 1990; Teng and Tzeng, 1989a; 1989b; Ma et al., 2014) and its method became suitable for uncertain situations and decisionmaking upon multiple criteria.

AHP develops the hierarchy of problems through the systematic analysis of pair comparison, determines the relative importance ratio of the factors and indicates the ranking of selections, as reference to select the best plans. In the application of AHP, there are 3 steps (Chang, 2013; Huang, 2015): 
Step 1-Construction of hierarchical structure.

First, construct the hierarchical structure to decide the relationship among different levels. AHP classifies complicated rating issues into the following four levels:

1. Problem-solving goals.

2. Accomplishment of target goals.

3. Decision of evaluation criteria of target.

4. Plans concerned.

Step 2-Calculation of criterion weights of different levels. There are 3 steps:

1. Construction of a Pairwise Comparison Matrix

2. Calculation of eigen value and eigen vector

3. Consistency testing

Step 3-Calculation of total hierarchical weights.

After calculating the weights of factors at different levels, this study obtains the total hierarchical weight. Finally, according to the weights of substitute plans, it determines the fittest plan of the ultimate goal. In group decision-making, the weights of substitute plans can be integrated.

Based on previous literature review, this study will construct the framework of decision-making to select Incentive Tour travel agencies by the Delphi Method and AHP.

\section{Research Method}

The factors were used to construct a decision-making model for the selection of Incentive Tour travel agencies by AHP. Based on the results of expert questionnaire, the formal survey was conducted and the supervisors in charge of Incentive Tours and excellent employees who participate in Incentive Tours were interviewed. Research Process shown as Fig. 1.

\section{Subjects}

\section{Subjects of Modified Delphi Method}

The subjects of Modified Delphi Method questionnaire included one professor in a related department of a university, one manager of a travel agency with an Incentive Tour department, two leaders and two guides.

\section{Subjects of the analytic hierarchy process}

The subjects of this study were supervisors in charge of Incentive Tours of firms and professional employees who have participated in Incentive Tours. Their opinions were used to construct the decision-making model for selecting Incentive Tour travel agencies. There were 8 subjects in the insurance industry, 7 subjects in the banking industry and 9 subjects in the direct sales industry (A total of 24 subjects).

\section{Investigation Tools}

1. Modified Delphi Method questionnaire

The questionnaire is aimed to collect data for constructing a decision-making model, thus, the expert questionnaire of the Modified Delphi Method was used to objectively integrate experts' opinions. Regarding the design of Modified Delphi Method questionnaire, according to decision-making assessment criteria, experts evaluate the effects of the decision-making model and scoring is based on 1-5 according to the importance of the assessment indicators. The questionnaire design is based on a semi-closed questionnaire survey and includes the column of "others". The experts provided their suggestions or opinions to modify the criteria as reference for this study.

\section{AHP questionnaire}

After the Modified Delphi Method questionnaire survey, this study obtained the assessment of the decision-making model. According to the research purposes and research framework, this study designed the questionnaire for a "decision-making model to select Incentive Tour travel agencies" and the purpose is to study and construct the weights of factors according to the results. At this stage, AHP is the main analytical method and the researcher conducts pair comparisons of the factors in the hierarchy, including 3 levels. The first level is the decision-making model; the second level is the level of targets and the third level is the assessment criteria. The hierarchical analysis process is shown, as follows:

1) Construction of AHP hierarchical structure

AHP consists of goals, elements or targets, subelements or assessment criteria and plans. AHP provides the framework to analyze problems. Basically, AHP develops a hierarchy on the complicated and non-structural problems by "stairway order" attributes. The relative weights of attributes are numerically indicated through subjective judgment in order to determine the general priority of a level.

2) AHP questionnaire design, survey and retrieval

Based on the hierarchical structure, this study designed an AHP questionnaire as the research tool to investigate the subjects. In order to effectively and rapidly retrieve questionnaires and maintain completeness of questionnaire data, this study conducted AHP questionnaires by written questionnaire survey, which were sent or personally delivered with stamped envelopes. Retrieval date was indicated in the questionnaires. In the 20 days from November 20 to December 10, 2014, this study distributed 24 questionnaires for empirical analysis. 


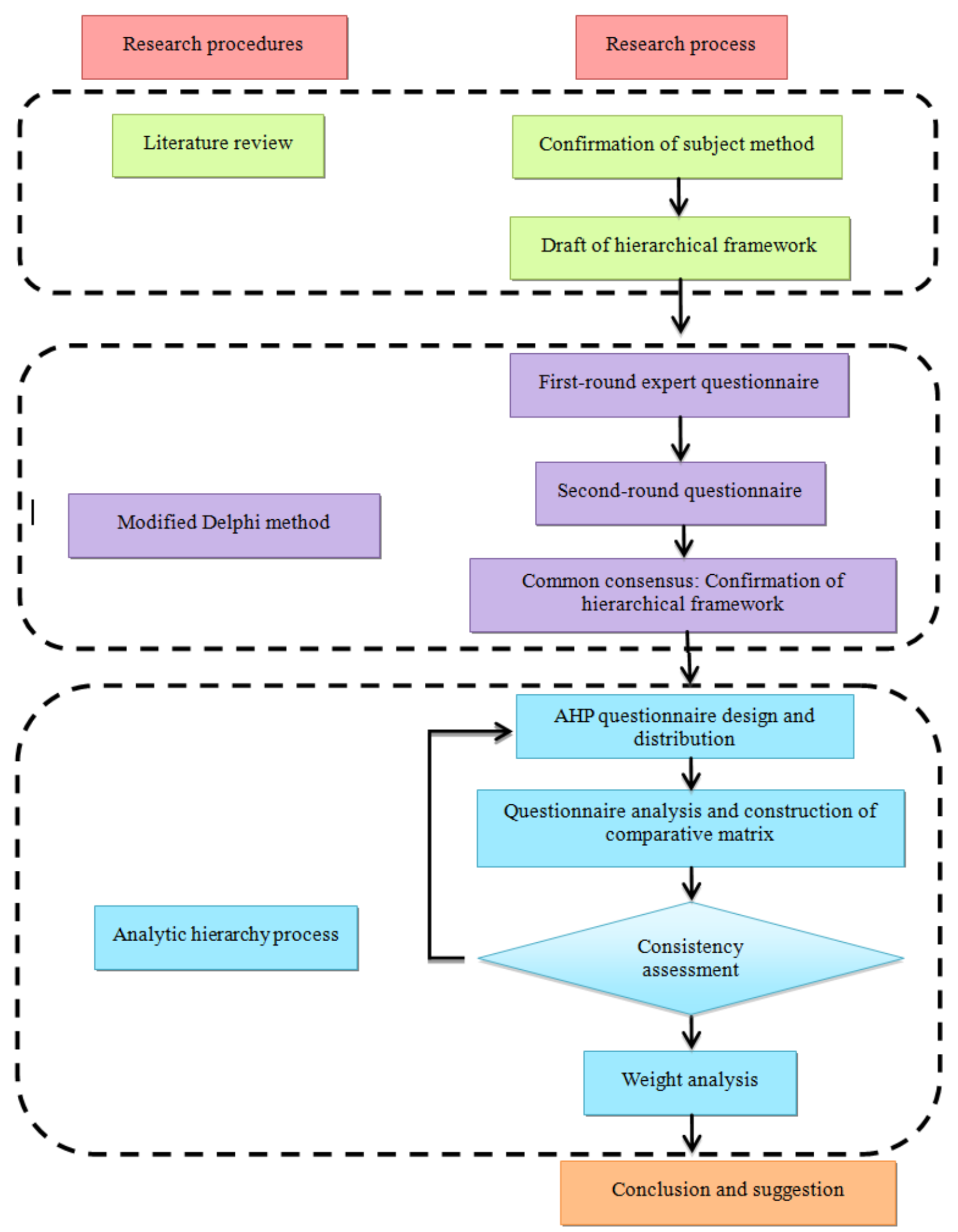

Fig. 1. Research steps 
3) Statistics, calculation and analysis of AHP questionnaire

A. Construction of Pair-wise Comparison Matrix:

We assume that at a certain level, there are factors $A_{1}, A_{2}, A_{3}, A_{4}, \ldots \ldots A_{n}$ and the weights of each factor are $W_{1}, W_{2}, W_{3}, \ldots \ldots W_{n}$ to construct a Pair-wise Comparison Matrix. The relative importance of any two elements $A_{i}$ and $A_{j}$ is shown by $a_{i j}$. The Pair-wise Comparison Matrix of factors $W_{n}, A_{1}, A_{2}, A_{3}, A_{4}, \ldots \ldots A_{n}$ is $A=\left[a_{i j}\right]$. When weights $W_{1}, W_{2}, W_{3}, \ldots \ldots W_{n}$ are known, the Pairwise Comparison Matrix $A=\left[a_{i j}\right]$ can be shown by Equation 1:

$A=\left[a_{i j}\right]=\left[\begin{array}{cccc}W_{1} / W_{1} & W_{1} / W_{2} & \ldots & W_{1} / W_{n} \\ W_{2} / W_{1} & W_{2} / W_{2} & \ldots & W_{2} / W_{n} \\ \cdot & \cdot & \ldots & \cdot \\ W_{n} / W_{1} & W_{n} / W_{2} & \ldots & W_{n} / W_{n}\end{array}\right]$
$a_{i j}=W_{i} / W_{j}, a_{j i}=W_{j} / W_{i}, i, j=1,2, \ldots \ldots, \mathrm{n}$

B. Acquisition of maximum eigen vector and eigen value According to the Pair-wise Comparison Matrix, we obtain the eigen vector and weight distribution of the maximum eigen value. Pair-wise Comparison Matrix A multiplied by weights of criteria as vector $\bar{W}$ is shown as Equation 2:

$$
\begin{aligned}
& \bar{W}=\left(W_{1}, W_{2}, W_{3}, \ldots \ldots W_{n}\right)^{T} \\
& A \bar{W}=\left[\begin{array}{cccc}
W_{1} / W_{1} & W_{1} / W_{2} & \ldots & W_{1} / W_{n} \\
W_{2} / W_{1} & W_{2} / W_{2} & \ldots & W_{2} / W_{n} \\
\cdot & \cdot & \ldots & \cdot \\
W_{n} / W_{1} & W_{n} / W_{2} & \ldots & W_{n} / W_{n}
\end{array}\right]\left[\begin{array}{c}
W_{1} \\
W_{2} \\
\cdot \\
W_{n}
\end{array}\right]=\lambda\left[\begin{array}{c}
W_{1} \\
W_{2} \\
\cdot \\
W_{n}
\end{array}\right]
\end{aligned}
$$

Pair-wise Comparison Matrix A multiplied by $\bar{W}$ is equal to $\lambda$ multiplied by $\bar{W} ; A \bar{W}=\lambda \bar{W} . \lambda$ is eigen value of $A$. It is the eigen vector of pair matrix $A$ to the eigen value.

In pair comparison, since $a_{i j}$ is obtained by subjective judgment, there is a gap with the real $W_{i} / W_{j}$ and it is $a_{i j} \approx W_{i} / W_{j}$. When $a_{i j}$ is slightly changed, the eigen value will also change. When the eigen value is not equal to $\lambda$, is the main eigen value and it is close to the eigen value of the theoretical weight. $\lambda_{\max }$ replaces $\lambda$, as shown in Equation 3:
$A \bar{W}=\lambda_{\max } \times \bar{W}$

The steps to obtain maximum eigen value $\lambda_{\max }$ is shown below. Pair-wise Comparison Matrix A multiplied by the obtained eigen vector $\bar{W}$ will result in a new vector $\bar{W}^{\prime}$, as shown in Equation 4 and 5:

$A \bar{W}=\bar{W}^{\prime}$

$\left[\begin{array}{cccc}W_{1} / W_{1} & W_{1} / W_{2} & \ldots & W_{1} / W_{n} \\ W_{2} / W_{1} & W_{2} / W_{2} & \ldots & W_{2} / W_{n} \\ \cdot & \cdot & \cdots & \cdot \\ W_{n} / W_{1} & W_{n} / W_{2} & \cdots & W_{n} / W_{n}\end{array}\right]\left[\begin{array}{c}W_{1} \\ W_{2} \\ \cdot \\ W_{n}\end{array}\right]=\left[\begin{array}{c}W_{1}^{\prime} \\ W_{2}^{\prime} \\ \cdot \\ W_{n}^{\prime}\end{array}\right]$

The known vectors are divided by the original vectors. The arithmetic mean of all values refers to $\lambda_{\max }$, as shown in Equation 6:

$\lambda \max =\frac{1}{n}\left(\frac{W_{1}}{W_{1}}+\frac{W_{2}}{W_{2}}+\ldots .+\frac{W_{n}^{\prime}}{W_{n}}\right)$

C. Consistency test.

It is difficult to require the subjects' consistency in pair comparison. Therefore, this study conducts consistency testing in order to obtain the Consistency Index (C.I.) and determine if Pair-wise Comparison Matrix of subjects' responses is a consistency matrix. When C.I. $=0$, it means the subjects' judgments are totally consistent. C.I. $\leq 0.1$ is the acceptable error. Hence, we can obtain the consistency (Saaty, 1980), as shown in Equation 7.

a. Consistence Index (C.I.):

C.I. $=\frac{\lambda_{\max }-n}{n-1}$

b. Consistency Ratio (C.R.)

In the positive reciprocal matrix of scale 1-9, C.I. at different levels is Random Index, R.I.) as shown in Table 1. At the same level, the ratio of C.I. and R.I. of the matrix is called C.R. = C.I./R.I. (Consistence Radio). When C.R. $\leq 0.1$, consistency is acceptable.

Table 1. Random indicators (Satty, 1977)

\begin{tabular}{llllllll}
\hline Number of order & 1 & 2 & 3 & 4 & 5 & 6 & 7 \\
\hline R. I & 0 & 0 & 0.58 & 0.9 & 1.12 & 1.24 & 1.32 \\
Number of order & 9 & 10 & 11 & 12 & 13 & 14 \\
R. I & 1.45 & 1.49 & 1.51 & 1.48 & 1.56 & 1.57 \\
\hline
\end{tabular}




\section{Results and Discussion}

This study aims to focus on the views of professors in related departments of universities, managers of travel agencies with an Incentive Tour department, guides and leaders; and by the Modified Delphi Method and AHP, analyze the decision-making model to select Incentive Tour travel agencies as reference for enterprises.

\section{Result of the Modified Delphi Method}

After two rounds of Modified Delphi Method questionnaire survey and according to experts' professional views and suggestions of revision, the questionnaire reached expert validity and the hierarchical framework was developed for of the decision-making model, as shown in Table 2.

\section{AHP Investigation Result}

By AHP, this study analyzes the proposed decisionmaking model. In the pair ratings of AHP, we must meet the transition of priority and intensity. However, in the process, as there can be errors caused by some factors, consistency testing is required. Therefore, Saaty (1980) suggests testing the consistency of the Pair-wise Comparison Matrix by C.I. and C.R. The results of consistency testing are as shown in Table 3. By calculation, the total weights and ranking of importance are obtained, as shown in Table 4.

Table 2. Result of modified Delphi method questionnaire survey

\begin{tabular}{|c|c|c|}
\hline Key factors of & Specialty of the team & Products are unique and different from competitors \\
\hline $\begin{array}{l}\text { select incentive } \\
\text { tour travel } \\
\text { agencies }\end{array}$ & $\begin{array}{l}\text { Hotel planning } \\
\text { Activity and itinerary } \\
\text { planning }\end{array}$ & $\begin{array}{l}\text { They propose the performance of Incentive Tour in the past } \\
\text { Department of Incentive Tour } \\
\text { High degree of cooperation and integration } \\
\text { Customized itinerary and transportation } \\
\text { Individual pick-up } \\
\text { Customized flights and ships } \\
\text { Large-scale group food service for Incentive Tour } \\
\text { Menu design for Incentive Tour } \\
\text { Activity design for the party } \\
\text { Comfort and level of restaurant } \\
\text { Hotels must provide customized service personnel } \\
\text { Decoration for Incentive Tour and welcoming activity in hotels } \\
\text { Software and hardware of hotels } \\
\text { Location of hotels } \\
\text { Special programs of tourist locations } \\
\text { Impressive and unforgettable experience design } \\
\text { Design of program is based on corporate culture and employees' characteristics } \\
\text { Arrangement of party creates the employees' sense of } \\
\text { achievement and honor } \\
\text { Locations match the needs of clients }\end{array}$ \\
\hline
\end{tabular}

\begin{tabular}{|c|c|c|c|c|c|c|}
\hline Goal & Principal criteria & C. I. & C. R. & Secondary criteria & C. I. & C. R. \\
\hline \multirow[t]{5}{*}{$\begin{array}{l}\text { Key } \\
\text { factors of select } \\
\text { incentive tour } \\
\text { travel agencies }\end{array}$} & Specialty of the team & 0.011 & 0.01 & $\begin{array}{l}\text { Products are unique and different from competitors } \\
\text { They propose the performance of Incentive Tour in the past } \\
\text { Department of Incentive Tour } \\
\text { High degree of cooperation and integration }\end{array}$ & 0.036 & 0.04 \\
\hline & $\begin{array}{l}\text { Transportation } \\
\text { planning }\end{array}$ & & & $\begin{array}{l}\text { Customized itinerary and transportation } \\
\text { Individual pick-up } \\
\text { Customized flights and ships }\end{array}$ & 0.02 & 0.036 \\
\hline & Food planning & & & $\begin{array}{l}\text { Large-scale group food service for Incentive Tour } \\
\text { Menu design for Incentive Tour } \\
\text { Activity design for the party } \\
\text { Comfort and level of restaurant }\end{array}$ & 0.021 & 0.023 \\
\hline & Hotel planning & & & $\begin{array}{l}\text { Hotels must provide customized service personnel } \\
\text { Decoration for Incentive Tour and welcoming activity in hotels } \\
\text { Software and hardware of hotels } \\
\text { Location of hotels }\end{array}$ & 0.01 & 0.012 \\
\hline & $\begin{array}{l}\text { Activity } \\
\text { and itinerary planning }\end{array}$ & & & $\begin{array}{l}\text { Special programs of tourist locations } \\
\text { Impressive and unforgettable experience design } \\
\text { Design of program is based on corporate culture } \\
\text { and employees' characteristics } \\
\text { Arrangement of party creates the employees' } \\
\text { sense of achievement and honor } \\
\text { Locations match the needs of clients }\end{array}$ & 0.019 & 0.017 \\
\hline
\end{tabular}




\begin{tabular}{|c|c|c|c|c|c|c|c|c|}
\hline Goal & Principal criteria & Weight & Ranking & Secondary criteria & $\begin{array}{l}\text { Hierarchical } \\
\text { weights }\end{array}$ & Ranking & $\begin{array}{l}\text { Total } \\
\text { weights }\end{array}$ & Ranking \\
\hline \multirow{23}{*}{$\begin{array}{l}\text { Key } \\
\text { factors of } \\
\text { select } \\
\text { tour travel } \\
\text { agencies }\end{array}$} & \multirow[t]{5}{*}{ Specialty of the team } & \multirow[t]{5}{*}{0.3365} & \multirow[t]{5}{*}{1} & Products are unique and different from competitors & 0.4822 & 1 & 0.16228 & 1 \\
\hline & & & & They propose the performance of I & & & & \\
\hline & & & & ncentive Tour in the past & 0.2280 & 2 & 0.07673 & 2 \\
\hline & & & & Department of Incentive Tour & 0.1254 & 4 & 0.0422 & 12 \\
\hline & & & & High degree of cooperation and integration & 0.1643 & 3 & 0.05529 & 4 \\
\hline & \multirow{3}{*}{$\begin{array}{l}\text { Transportation } \\
\text { planning }\end{array}$} & \multirow[t]{3}{*}{0.1406} & \multirow[t]{3}{*}{5} & Customized itinerary and transportation & 0.5115 & 1 & 0.07191 & 3 \\
\hline & & & & Individual pick-up & 0.3251 & 2 & 0.04571 & 9 \\
\hline & & & & Customized flights and ships & 0.1635 & 3 & 0.02298 & 20 \\
\hline & \multirow[t]{4}{*}{ Food planning } & \multirow[t]{4}{*}{0.1694} & \multirow[t]{4}{*}{3} & Large-scale group food service for Incentive Tour & 0.1413 & 4 & 0.02393 & 19 \\
\hline & & & & Menu design for Incentive Tour & 0.2311 & 3 & 0.03914 & 14 \\
\hline & & & & Activity design for the party & 0.3019 & 2 & 0.05114 & 6 \\
\hline & & & & Comfort and level of restaurant & 0.3258 & 1 & 0.05519 & 5 \\
\hline & \multirow[t]{5}{*}{ Hotel planning } & \multirow[t]{5}{*}{0.1534} & \multirow[t]{5}{*}{4} & Hotels must provide customized service personnel & 0.2365 & 3 & 0.03628 & 15 \\
\hline & & & & Decoration for Incentive Tour and & & & & \\
\hline & & & & welcoming activity in hotels & 0.283 & 2 & 0.04342 & 11 \\
\hline & & & & Software and hardware of hotels & 0.3091 & 1 & 0.04741 & 8 \\
\hline & & & & Location of hotels & 0.1714 & 4 & 0.02629 & 18 \\
\hline & \multirow[t]{6}{*}{$\begin{array}{l}\text { Activity and } \\
\text { itinerary planning }\end{array}$} & \multirow[t]{6}{*}{0.2002} & \multirow[t]{6}{*}{2} & Special programs of tourist locations & 0.2181 & 2 & 0.04366 & 10 \\
\hline & & & & Impressive and unforgettable experience design & 0.2488 & 1 & 0.04981 & 7 \\
\hline & & & & $\begin{array}{l}\text { Design of program is based on corporate culture } \\
\text { and employees' characteristics }\end{array}$ & 0.1617 & 5 & 0.03238 & 17 \\
\hline & & & & Arrangement of party creates the employees' & & & & \\
\hline & & & & sense of achievement and honor & 0.1985 & 3 & 0.03973 & 13 \\
\hline & & & & Locations match the needs of clients & 0.1729 & 4 & 0.03462 & 16 \\
\hline
\end{tabular}

\section{Hierarchical Weights of Principal Criteria and Ranking}

The principal criteria level includes 5 dimensions. The C.I. and C.R. of the total dimension matches the suggestion of Saaty $(<0.1)$. After pair comparison, at the first level of the sub-dimensions, the ranking of importance is, as follows: Specialty of the team, activity and itinerary planning, food planning, hotel planning and transportation planning.

For experts, the specialty of the team, activities and itinerary planning are extremely important (54\%). Hence, travel agencies that are identified by enterprises and have the capacity to undertake important Incentive Tours, must have high-level specialty of the team, excellent activities and itinerary planning ability. Enterprises that are in need can treat the results as reference for future Incentive Tours.

The weights of hotel planning and transportation planning are relatively low; therefore, experts neglect these two dimensions. In other words, most excellent employees in Incentive Tours are not concerned about hotel or transportation planning. However, although weight of transportation planning is the lowest at this level, customized transportation is in the top 3 of the overall weight. Therefore, most experts pay attention to customized transportation.

\section{Overall Weights and Ranking}

1. Top 10 of the relative weights of the decision-making model to select Incentive Tour travel agencies.

Regarding the 20 sub-criteria, the hierarchical weights and overall weight are listed after hierarchical analysis. The top ten are as follows: Products are unique and different from competitors, They propose the performance of Incentive Tours in the past, Customized itinerary and transportation, High degree of cooperation and integration, Comfort and level of restaurant, Activities design for the party, Impressive and unforgettable experience design, Software and hardware of hotels, Individual pick-up and Special programs of tourist spots.

For all experts of the AHP questionnaire in this study, "Products are unique and different from competitors" is the top 1 of the overall weight. Therefore, Incentive Tour travel agencies must have unique products in order to stand out among competitors. During selection, the enterprises should focus on the uniqueness of travel products.

"They propose the performance of an Incentive Tour in the past" is the second of the overall weight. Hence, most experts pay attention to the experience. Travel agencies with experience are more reliable. They are willing to authorize important Incentive Tours to these travel agencies.

Among the 5 principal criteria, regarding transportation planning with the lowest weight, the sub-criteria of customized transportation and individual pick-up are Top 3 and Top 9 of the overall weight, respectively. Therefore, excellent employees who are invited to participate in an Incentive Tour all expect the trip to be different from a general group tour.

Good hotels are necessary in Incentive Tours. Therefore, the selected hotels must have high-level software and hardware, comfortable restaurants and 
exclusive party activity design. It is the main reason that these three sub-criteria are in the Top 10.

In addition, the itinerary during the day time is an attractive characteristic of an Incentive Tour. Impressive and unforgettable experience design and special programs of tourist locations will provide wonderful memories for the participants.

2. The last 5 relative weights of the decision-making model to select Incentive Tour travel agencies

In the 20 sub-criteria, after calculation of hierarchical analysis, this study lists hierarchical weights and overall weight. The last five are, as follows: Location match the needs of clients, Design of program is based on corporate culture and employees' characteristics, Location of hotels, Largescale group food service for Incentive Tour and Customized flights and ships. Therefore, these 5 subcriteria influence the selection of Incentive Tour travel agencies the least. It shows that most participants in an Incentive Tour neglect these five factors.

\section{Conclusion}

By experts' assistance and participation, this study obtained the weights of factors in the decision-making model to select Incentive Tour travel agencies and according to the results, it establishes an objective evaluation standard. In the hierarchical framework, there are 5 principal criteria and 20 sub-criteria, as follows:

- Items of specialty of the team: Products are unique and different from competitors. They propose the performance of Incentive Tours in the past, a department of Incentive Tour and high degree of cooperation and integration

- Items of transportation planning: Customized itinerary and transportation, individual pick-up and customized flights and ships

- Items of food planning: Large-scale group food service for Incentive Tour, menu design for Incentive Tour, activity design for the party and comfort and level of restaurant

- Items of hotel planning: Hotels must provide customized service personnel, decoration for the Incentive Tour, welcoming activity in hotels, software and hardware of hotels and locations of hotels

- Items of activity and itinerary planning: Special programs of tourist locations, impressive and unforgettable experience design, the design of the program is based on corporate culture and employees' characteristics, arrangement of the party creates the employees' sense of achievement and honor and locations match the needs of clients

\section{Acknowledgement}

This study was developed and planned by Prof. HanChen Huang, Prof. Pei-Ying Wu and Prof. Su-Ling Wu and accomplished with the assistance of Chin-Yuan Wu. Under the advices of Prof. Pei-Ying Wu and Prof. SuLing $\mathrm{Wu}$, Chin-Yuan $\mathrm{Wu}$ probed into this research topic and tries to obtain the master's degree.

\section{Author's Contributions}

This study is the result of the full and equal collaboration of all the authors.

\section{Ethics}

The authors have no conflicts of interest in the development and publication of this research.

\section{References}

Chang, H.I., 2013. The evaluation model of employability in tourism industry. Adv. Inform. Sci. Service Sci., 5: 159-168. DOI: 10.4156/AISS.vol5.issue 11.20

Chang, K.W. and Y.H. Chen, 2008. The case study of incentive tourism. J. Sports Knowledge, 5: 54-66.

Chen, P.C., 2002. The study of incentive travel and it's impacts on work attitude. MSc Thesis, Institute of Tourism, Shih Hsin University, Taiwan.

Chiang, I.C., 2004. Motivational effect of corporation for incentive travel system-empirical study on a Tai insurance company. MSc Thesis, Institute of Tourism, Shih Hsin University, Taiwan.

Hampton, A., 1987. The UK incentive travel market: A user's view. Eur. J. Market., 21: 10-20. DOI: 10.1108/EUM0000000004713

Hastings, B., J. Kiely and T. Watkins, 1988. Sales force motivation using travel incentives: Some empirical evidence. J. Personal Selling Sales Manage., 2: 43-51.

DOI: $10.1080 / 08853134.1988 .10754490$

Huang, H.C., 2015. Applying fuzzy analytic hierarchy process to construct a festival planner selection model. Adv. Inform. Sci. Service Sci., 7: 52-61.

Ma, H., Y. Cao and N. Cai, 2014. On evaluation of index system of new socialist countryside in ethnic regions of china: An AHP-based fuzzy approach. Int. J. Soft Comput. Applic., 2: 1-7.

Murry, J.W. and J.O. Hammons, 1995. Delphi: A versatile methodology for conducting qualitative research. Rev. Higher Educ., 4: 423-436.

Saaty, T.L., 1977. A scaling method for priorities in hierarchical structures. J. Math. Psychol., 15: 234-281. DOI: 10.1016/0022-2496(77)90033-5

Saaty, T.L., 1980. The Analytic Hierarchy Process. 1st Edn., McGraw-Hill, Bronson, TX., ISBN-10: 0070543712, pp: 287. 
Saaty, T.L., 1990. The Analytic Hierarchy Process: Planning, Priority Setting, Resource Allocation. 2nd Edn., RWS Publications, Pittsburgh, ISBN-10: 0962031720, pp: 287.

SITE, 2014. The society of incentive travel executives. http://www.site-intl.org

STB, 2014. Singapore tourism board.

Stolovitch, H., 2002. Incentives motivation and work place performance: Research and best practice. SITE Foundation.

TBMOTC, 2009. Taiwan incentive tour guidebook. TBMOTC, K\&A International.

Teng, J.Y. and G. H. Tzeng, 1989a. Content characteristics and application of Analytic Hierarchy Process (AHP) (I). J. Chinese Statistical Associat., 27: 6-22.
Teng, J.Y. and G.H. Tzeng, 1989b. Content characteristics and application of Analytic Hierarchy Process (AHP) (II). J. Chinese Statistical Associat., 27: 1-19.

Wang, T.C., 2009. Incentive travel in China: Blue ocean strategy approach. MSc Thesis, National Taiwan Normal University, Taiwan.

Yung, C.Y., S.H. Tsaur, H.C. Niou and L.T. Lin, 2008. Operation and management of travel industry. Chinese Cheng Culture. 